\title{
Continuous Veno-Venous High Cut-Off Hemodialysis Compared to Continuous Veno-Venous Hemodiafiltration in Intensive Care Unit Acute Kidney Injury Patients
}



\author{
Sanjeet Balgobin ${ }^{a, b}$ Marion Morena ${ }^{c}$ Vincent Brunot ${ }^{a} \quad$ Noemie Besnard $^{a}$ \\ Delphine Daubin $^{a}$ Laura Platon ${ }^{a}$ Romaric Larcher ${ }^{a, c}$ Laurent Amigues ${ }^{a}$ \\ Liliane Landreau $^{a} \quad$ Anne-Sophie Bargnoux ${ }^{c, d}$ Anne-Marie Dupuy ${ }^{d}$ \\ Jean-Paul Cristol ${ }^{c, d}$ Kada Klouche ${ }^{a, c}$

\begin{abstract}
${ }^{a}$ Department of Intensive Care Medicine, Montpellier University Hospital, Montpellier, France; ${ }^{b}$ Department

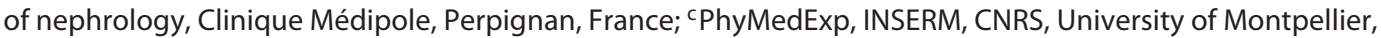
Montpellier, France; ${ }^{d}$ Department of Biochemistry and Hormonology, Montpellier University Hospital,

Montpellier, France
\end{abstract}

\section{Keywords}

Acute kidney injury · Continuous renal replacement therapy · Continuous hemodialysis · Continuous hemodiafiltration $\cdot$ High-flux membrane $\cdot$ High cut-off membrane $\cdot$ Cytokines $\cdot$ Oxidative stress

\begin{abstract}
Aims: High cut-off (HCO) continuous veno-venous hemodialysis (CVVHD) was compared to high-flux membrane (HFM) continuous veno-venous hemodiafiltration (CVVHDF) in intensive care unit (ICU) acute kidney injury (AKI) in terms of efficiency, hemodynamic tolerance, medium-sized molecules removal, albumin loss, and inflammatory system activation. Methods: In a prospective cross-over randomized study, $10 \mathrm{AKI}$ patients underwent successively $\mathrm{HCO}$ (Ultraflux $\mathrm{EmiC}_{2}$ : $\beta_{2}$-microglobulin $\left[\beta_{2} M\right]$ sieving coefficient [SC]: 0.9) CVVHD and HFM (Ultraflux AV1000S: $\beta_{2}$ M SC: 0.65) CVVHDF.
\end{abstract}

Results: Over the 20 sessions, hypotensive and febrile episodes, reduction rates of urea, creatinine, and $\beta_{2} M$ were similar in both modalities. Though dialysis dose was higher with CVVHDF (36 \pm 4 vs. $21 \pm 6 \mathrm{~mL} / \mathrm{Kg} / \mathrm{h}$ ), urea, creatinine, and $\beta_{2} \mathrm{M}$ instantaneous and plasmatic clearances did not differ except for urea at $12 \mathrm{~h}$. Protein loss, superoxide anion production, cytokines, and growth factors variations were also comparable. Conclusion: HCO CVVHD is well tolerated and is as effective as HFM CVVHDF in clearance of solutes and removal of $\beta_{2} M$. It induces neither protein loss nor overproduction of superoxide anion. Video Journal Club "Cappuccino with Claudio Ronco" at http://www.karger.com/?doi=489082.

(c) 2018 S. Karger AG, Basel

The study was conducted in the department of intensive care medicine of Lapeyronie Hospital in Montpellier, France.

\section{KARGER}

(c) 2018 S. Karger AG, Basel

E-Mail karger@karger.com

www.karger.com/bpu
Kada Klouche, MD, $\mathrm{PhD}$

Intensive Care Medicine Department

University of Montpellier, Lapeyronie Hospital

371, Av Doyen Gaston Giraud, FR-34295 Montpellier (France)

E-Mail k-klouche@chu-montpellier.fr 


\section{Introduction}

Acute kidney injury (AKI) requiring renal replacement therapy (RRT) occurs in 5-6\% of critically ill patients and is associated with high mortality and significant health resource utilization [1-5]. Currently available modalities of RRT include intermittent and continuous RRTs. Though a better survival using continuous compared with intermittent RRT has not been evidenced [69], the former has gained wide application in intensive care units (ICUs), often supplanting intermittent modalities because of the belief that it is better tolerated in hemodynamically unstable patients $[10,11]$. The removal of middle molecules, particularly inflammatory response mediators such as cytokines and complement, has been involved in this intradialytic hemodynamic improvement [12-14]. However, this removal may be provided only by convection exchange using high-flux membrane (HFM) [15]. Yet, the main diffusive solute clearance involved in hemodialysis, which may be perceived as a disadvantage regarding to the elimination of larger molecules, may be improved by the use of high cut-off membrane (HCO).

Current HFMs were mainly designed to provide increased removal of $\beta 2$-microglobulin $\left(\beta_{2} \mathrm{M}\right)$ and their use has successfully led to a reduction in the incidence of dialysis-related amyloid. However, middle molecules and protein-bound toxins remained inadequately removed by high-flux hemodialysis [16]. A new generation of dialysis membranes was then performed, an HCO membrane with higher molecular weight cut-offs at 50 to $60 \mathrm{kDa}$. Hemodialysis with HCO membrane has been well studied in settings of chronic hemodialyzed patients. It shows an improved survival, morbidity, and mortality rate [17-19]. Yet, the use of HD with HCO membrane remains poorly investigated among ICU patients with AKI [20]. Some ICU departments mainly use renal replacement diffusive therapies, which may lack in middlesized molecule purification. Using HCO membranes could significantly enhance the removal of these molecules mimicking convective therapies. However, the larger pore size could expose to a significant loss of albumin in the effluent [21]. Also, these membranes may activate the inflammatory system by retro-diffusion [22], even if the usual utilization of sealed, sterile, and singleuse solutions is considered to ensure the fluids microbial integrity of the dialysate. Indeed, a significant bacterial contamination of the industry-standard circuitry and bicarbonate replacement fluid has been previously reported $[23,24]$.

HCO Hemodialysis for AKI Patients



Fig. 1. Flowchart and design of the study. CVVHD, continuous veno-venous hemodialysis; CVVHDF, continuous veno-venous hemodiafiltration; HCO, high cut-off; HFM, high-flux membrane.

This study was therefore undertaken to evaluate the efficiency of an HCO membrane continuous veno-venous hemodialysis (CVVHD) compared to a conventional HFM continuous veno-venous hemodiafiltration (CVVHDF) in terms of clinical and hemodynamic tolerance, medium-sized molecules removal, albumin loss, and inflammatory system activation in ICU AKI patients.

\section{Materials and Methods}

In our Department of Intensive Care Medicine, we routinely use CVVHDF with HFM. Since 2016, we use HCO membrane to perform CVVHD. We performed a prospective cross-over study from February to October 2016 to compare clinical and biological effects of both modalities. Our objective was to evaluate the performance of $\mathrm{HCO}$ membrane using diffusive therapy and we chose to compare it to convective therapy knowing its effects regarding to middle molecules removal.

All participants provided written informed consent and the evaluation was both performed according to the principles of the Declaration of Helsinki and approved by the Ethics Committee of Montpellier. Blood samples were gathered in dry tubes from patients, and were then stored at $-80^{\circ} \mathrm{C}$ during a mean period of 3 $( \pm 1)$ years. According to the French law, this collection was registered to the "Ministère de l' Enseignement supérieur et de la Recherche" (number DC-2008-417).

\section{Patients}

Patients consecutively admitted to ICU with AKI requiring RRT were included in the study. Exclusion criteria included pregnancy, age $<18$ years, previous chronic renal failure (baseline serum creatinine $>2 \mathrm{mg} / \mathrm{dL}$ or $180 \mu \mathrm{mol} / \mathrm{L}$ ), AKI of obstructive, glomerular or vascular etiology, treatment limitation or presumed survival $<48 \mathrm{~h}$, aplasia, and hematologic malignancy. RRT was initiated according to KDIGO guidelines [25].

Ten patients were included and every patient was submitted to two 24-h sessions: a CVVHDF session using an HFM followed, after a wash-out period of $24 \mathrm{~h}$ by a CVVHD session using an HCO membrane. The hemofilter was changed at every new RRT session. The order of sessions was randomized and changed simultaneously at each included patient as shown in the cross-over chart (Fig. 1). 
Main Characteristics of RRTs

CVVHDF was performed via a predilution mode using a Multifiltrate monitoring machine and $1.8 \mathrm{~m}^{2}$ polysulfone hemofilter AV1000S (Fresenius Medical Care, Bad Hamburg, Germany). Blood flow was maintained at $200 \mathrm{~mL} / \mathrm{min}$. Infusate and dialysate flow rates were at $2,000 \mathrm{~mL} / \mathrm{h}$ using a sterile bicarbonate buffer solution. Characteristics of the HFM were Ultraflux AV1000S, material: polysulfone, surface: $1.80 \mathrm{~m}^{2}$, sieving coefficient of $\beta_{2} \mathrm{M}$ : 0.65, albumin: 0.001 , inulin: 1 ; thickness of fibers: $35 \mu \mathrm{m}$ and inner diameter: $220 \mu \mathrm{m}$.

CVVHD was performed using the same generator and $1.80 \mathrm{~m}^{2}$ polysulfone hemofilter Ultraflux $\mathrm{EMiC}_{2} \mathrm{HCO}$ membrane (Fresenius Medical Care, Bad Hamburg, Germany). Blood flow was maintained at $200 \mathrm{~mL} / \mathrm{min}$ and dialysate flow rate at $2,000 \mathrm{~mL} / \mathrm{h}$ using a sterile bicarbonate buffer solution. Characteristics of the $\mathrm{HCO}$ membrane were: Ultraflux $\mathrm{EMiC}_{2}$, material: polysulfone, surface: $1.80 \mathrm{~m}^{2}$, sieving coefficient of $\beta_{2} \mathrm{M}: 0.9$, albumin: 0.01 , inulin: 1 , thickness of fibers: $35 \mu \mathrm{m}$ and inner diameter: $220 \mu \mathrm{m}$.

In both RRT modalities, dialysate temperature was set at $36^{\circ} \mathrm{C}$ and anticoagulation was achieved using heparin at maintenance doses of $200 \mathrm{IU} / \mathrm{h}$.

\section{Clinical Tolerance and Solutes Control of RRT}

Clinical tolerance of both treatments was investigated by collecting pulse, temperature, and mean arterial blood pressure readings at baseline and every 30 min during each session. An intradialytic hypotensive event was defined by a $20 \%$ reduction of mean arterial blood pressure or by an increase in vasoconstrictive agents' dose.

Blood samples were drawn from the arterial port of the venous catheter immediately before session, regularly every $6 \mathrm{~h}$ during treatment and at the end of $24 \mathrm{~h}$ session for measurements of urea, creatinine, protein, albumin, $\beta_{2}$ M. Blood samples were collected at the end of the treatment by standard stop-flow technique [26]. Throughout the session we collected the effluent and measured in it the levels of urea, creatinine, albumin, and protein.

Delivered clearance was directly calculated by the monitor as the total effluent amount and was expressed in $\mathrm{mL} / \mathrm{min}$ [15]. We also used the Urea Reduction Ratio to assess the efficiency of the session according to the formula: Urea Reduction Ratio $=($ Serum Urea $_{\text {preRRT }}$ - Serum Urea postRRT $_{\text {(Serum Urea }}$ (SreRRT). Reduction rates of creatinine and $\beta_{2} \mathrm{M}$ were also calculated according to $(\mathrm{Cb}-\mathrm{Cd}) / \mathrm{Cb}$; where $\mathrm{Cb}$ stands for the concentration of solute at the beginning and $\mathrm{Cd}$ at the end of the session.

To evaluate instantaneous clearance (IC) of urea, creatinine, and $\beta_{2} \mathrm{M}$, we performed blood tests at $\mathrm{H}_{6}, \mathrm{H}_{12}$, and $\mathrm{H}_{18}$ twice on the arterial and on the venous line of the dialysis circuit and used the following formula: $\mathrm{IC}=([\mathrm{Ca}-\mathrm{Cv}] / \mathrm{Ca}) \times$ blood flow rate; where $\mathrm{Ca}=$ concentration of the solute in the arterial line and $\mathrm{Cv}=$ concentration of the solute in the venous line and blood flow rate $(\mathrm{mL} / \mathrm{min})$.

Plasmatic clearance (PC) of each solute was determined according to the following formula: IC $\times(1-0.00107 \times$ protidemia $) \times([$ coefficient of partition $\times$ Hematocrite $]+1$ - Hematocrit), where coefficient of partition for urea and creatinine equals 1 , and for $\beta_{2} \mathrm{M} 0.9$ with HCO and 0.65 with HFM.

\section{Evaluation of Inflammatory Mediators During the Session} and Potential Cytokines Removal

A potential intradialytic inflammatory risk and cytokines removal was evaluated by the measurement of oxidative stress pro- duction and of plasma concentrations of proinflammatory $(\mathrm{Tu}-$ mor Necrosis factor alpha [TNF- $\alpha$ ], Interleukin 6 [IL-6], IL-1 $\alpha$, IL-1 $\beta$, IL-8, IL-2) and anti-inflammatory (IL-4, IL-10) cytokines, Epidermal growth factor (EGF), Vascular Endothelial growth factor (VEGF), and Macrophage Chemoattractive Protein-1 (MCP-1) before and after sessions.

Determination of Superoxide $\left(\mathrm{O}_{2}^{-}\right)$Anion Production by Whole Blood

Superoxide $\left(\mathrm{O}_{2}{ }^{\circ}\right)$ anion production was measured in blood samples before and after RRT sessions. It was determined in 200 $\mu \mathrm{L}$ of fresh whole blood (treated immediately after collection) diluted in $820 \mu \mathrm{L}$ of DMEM medium and $200 \mu \mathrm{L}$ of lucigenin $\left(1.5 \times 10^{-4} \mathrm{~mol} / \mathrm{L}\right)$ (Sigma Chemical, Saint Quentin Fallavier, France) [27]. After a 20 -min incubation at $37^{\circ} \mathrm{C}$ under gentle agitation, whole blood was stimulated by using Phorbol $12-\mathrm{My}$ ristate 13 -Acetate (PMA; $10^{-7} \mathrm{M}$ ) and the luminescence was immediately recorded at $37^{\circ} \mathrm{C}$ by means of a Victor Wallac luminometer (Perkin Elmer, Turku, Finland). Luminescence intensity was normalized to leukocyte count. Response of PMA-free whole blood (basal $\mathrm{O}_{2}{ }^{\circ}$ - production) incubated simultaneously was used as control and considered equal to $100 \%$. To rule out autoproduction of $\mathrm{O}_{2}^{\circ}{ }^{\circ}$ by lucigenin or by plasma compounds, $\mathrm{O}_{2}^{\circ}$ - production was determined in whole blood, de-leukocyted blood, plasma, and culture medium. Imprecision studies of $\mathrm{O}_{2}{ }^{\circ-}$ production measure were as follows: intra-assay $\mathrm{CV}=3.5 \%$ (basal $\mathrm{O}_{2}{ }^{\mathrm{o}}$ production) and 3.9\% (PMA-stimulated $\mathrm{O}_{2}{ }^{\circ-}$ production); interassay $\mathrm{CV}=5.0 \%$ (basal $\mathrm{O}_{2}{ }^{\circ-}$ production) and 9.7\% (PMA-stimulated $\mathrm{O}_{2}{ }^{\mathrm{o}-}$ production).

Determination of Plasmatic Cytokines and Growth

Factors Measurements

Pre- and post-RRT sessions blood samples were immediately centrifuged at $1,000 \mathrm{~g}$ for $10 \mathrm{~min}$ at $4{ }^{\circ} \mathrm{C}$ and stored at $-80^{\circ} \mathrm{C}$ until use. A panel of cytokines was determined on frozen plasma using a proteomic approach on an Evidence Investigatore biochip system (Randox, Mauguio, France). This proteomic method allows the simultaneous determination of TNF- $\alpha$, IL- $1 \alpha$, IL- $1 \beta$, IL-2, IL-4, IL-6, IL-8, IL-10, EGF, VEGF, and MCP-1 levels. After the addition of a sample $(100 \mu \mathrm{L})$ to the biochip, the degree of binding of each analyst to its specific ligand is determined using a chemiluminescence light source and quantified using a supercooled charge-coupled camera and image-processing software [28].

\section{Statistical Analysis}

Statistical analysis was performed using SAS Entreprise Guide version 4.1. We first performed a descriptive analysis by computing frequencies and percentages for categorical data, and means, standard deviations, quartiles, and extreme values for continuous data. We also checked for normality of continuous data distribution using Shapiro-Wilk's tests. Second, we conducted a cross-over analysis between the 2 groups of RRT. For qualitative variables, comparisons were performed using chi-square test or by using the Fisher exact test when the conditions of validity of the chi-square were not verified. For quantitative variables, comparisons were carried out using the Student $t$ test or Wilcoxon test according to distribution.

A value of $p<0.05$ was considered significant. 
Table 1. Epidemiological data of patients

\begin{tabular}{lc}
\hline Patient characteristics & $n=10$ \\
\hline Age, years, median (IQR 25-75) & $67(57-72)$ \\
Gender, male, $n$ (\%) & $7(70)$ \\
SAPS II, median (IQR 25-75) & $60(52-67)$ \\
SOFA score, median (IQR 25-75) & $13(11-15)$ \\
KDIGO score & 3 \\
Mechanical ventilation, $n(\%)$ & $9(90)$ \\
Vasoactive support, $n(\%)$ & $10(100)$ \\
Causes of AKI, $n(\%)$ & $7(70)$ \\
$\quad$ Septic & $2(20)$ \\
Ischemic & $1(10)$ \\
$\quad$ Miscenalleous &
\end{tabular}

AKI, acute kidney injury (AKI may be multifactorial); ICU, Intensive Care Unit, SAPS II, Simplified acute Physiologic Score; SOFA, sequential organ failure assessment; KDIGO score, Kidney disease improving global outcomes.

\section{Results}

\section{Patient Characteristics}

During the study, it was found that 48 patients had AKI; of these, 15 (30\%) were on RRT. Fourteen patients entered the study, but 4 were excluded: 2 patients died and 2 recovered from their kidney failure after the first RRT session.

Age, gender, cause of AKI, and severity scores of the 10 included patients are listed in Table 1 . The cause of AKI was mainly septic. All patients were anuric, treated by vasoactive agents and most of them ventilated. All patients were discharged alive from the ICU.

Clinical and Hemodynamic Tolerance of RRT Sessions Among the 20 RRT sessions analyzed, an intradialytic hypotensive event was observed during 3 sessions accounting for a mal-tolerated session's rate at $15 \%$. More episodes of severe hypotension occurred with HFM $(2 / 10)$ than with HCO $(1 / 10)$ without significant difference $(p=0.46)$. No pyrogenic reactions occurred among all sessions performed.

\section{RRT Efficiency and Solutes Control}

HDF accounted for a dialysate and infusate rate of $4,000 \mathrm{~mL} / \mathrm{h}$ inducing a dialysis dose of $36 \pm 4 \mathrm{~mL} / \mathrm{kg} / \mathrm{h}$ as compared to only $2,000 \mathrm{~mL} / \mathrm{h}$ of dialysate rate and a dialysis dose of $21 \pm 6 \mathrm{~mL} / \mathrm{kg} / \mathrm{h}$ in HCO CVVHD. As expected, efficiency was better with CVVHDF, but differences did not remain statistically different. Indeed, urea and creatinine Reduction Ratios were at 37.5 vs. $53 \%$, and 38.5 vs. $49.9 \%, p=0.1$; HCO vs. HFM respectively. Furthermore, urea and creatinine clearances were at $22 \pm 5$ vs. $28 \pm 6 \mathrm{~mL} / \mathrm{min}$, and $21 \pm 6$ vs. $29 \pm 5 \mathrm{~mL} / \mathrm{min} ; p>0.05$; $\mathrm{HCO}$ vs. HFM respectively.

Despite the lower flow rate, $\beta_{2} \mathrm{M}$ reduction rate was higher with HCO CVVHD without reaching statistical difference (54.4 vs. $47.6 \%, p=0.3$; HCO vs. HFM).

\section{Comparison of the Two Membranes}

Instantaneous Clearances

The measurements of urea, creatinine, and $\beta_{2} \mathrm{M}$ IC at $\mathrm{H}_{6}, \mathrm{H}_{12}, \mathrm{H}_{18}$ of RRT sessions with both membranes are depicted graphically in Figure 2. As we expected, urea and creatinine IC were higher with HFM CVVHDF as compared to HCO CVVHD, but the difference was significant only for urea clearance at $\mathrm{H}_{12}(33.1$ vs. $52.6 \mathrm{~mL} / \mathrm{min}, p=$ 0.03 ; HCO vs. HFM). It is noteworthy that urea and creatinine clearances remained stable all along the HCO CVVHD session, above $30 \mathrm{~mL} / \mathrm{min}$.

IC of $\beta_{2} \mathrm{M}$, a middle-sized molecule, was comparable with both RRT modalities. Though RRT flow rates were smaller, HCO CVVHD reached a $\beta_{2} \mathrm{M}$ clearance level at $30 \mathrm{~mL} / \mathrm{min}$ as did HFM CVVHDF.

\section{Plasmatic Clearances}

Urea, creatinine, and $\beta_{2}$ M PCs at $\mathrm{H}_{6}, \mathrm{H}_{12}$, and $\mathrm{H}_{18}$ of RRT sessions with both membranes are depicted graphically in Figure 3. Urea and creatinine PCs were higher with HFM CVVHDF as compared to HCO CVVHD sessions, but the difference was significant only for urea clearance at $\mathrm{H}_{12}$ ( 31.5 vs. $49.9 \mathrm{~mL} / \mathrm{min}, p=0.03$; HCO vs. HFM). PCs of $\beta_{2} \mathrm{M}$ were similar with both membranes at different times of RRT sessions, above $20 \mathrm{~mL} / \mathrm{min}$.

\section{Protein Loss}

At the end of $24 \mathrm{~h}$ of RRT, albuminemia decreased slightly with both membranes. A comparable decrease was observed with HFM and HCO, $2.1 \pm 6.5$ vs. $2.5 \pm 2.9 \mathrm{~g} / 24 \mathrm{~h}$ respectively. The amount of protein in total effluent was at $3.8 \pm 4.6$ vs. $7.2 \pm 2.8 \mathrm{~g} / 24 \mathrm{~h}$ with HFM and HCO respectively with $p=0.15$. Albumin was undetectable in the effluent for each membrane. We must acknowledge that no albumin was administered intravenously to the patients.

Superoxide Production, Inflammatory Mediators, and Growth Factors

Mean basal and PMA-stimulated production of $\mathrm{O}_{2}{ }^{\circ-}$ anion by leukocytes did not differ before and after sessions with both membranes (Fig. 4). 


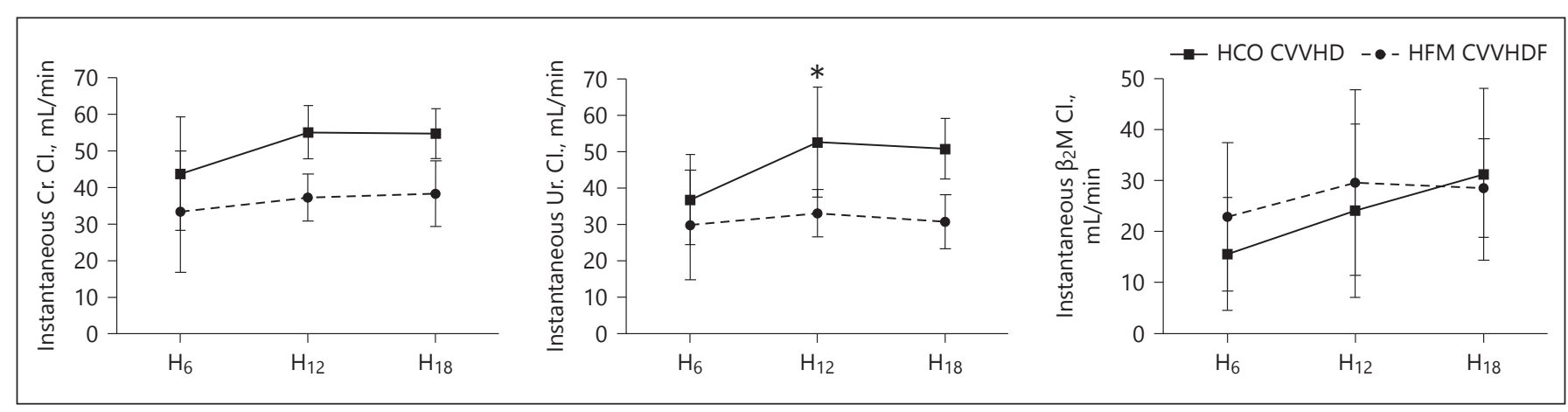

Fig. 2. ICs of creatinine, urea and $\beta_{2} \mathrm{M}$ at $\mathrm{H}_{6}, \mathrm{H}_{12}, \mathrm{H}_{18}$ of $\mathrm{HCO}$ CVVHD and of HFM CVVHDF. Dialysis dose was at $21 \pm 6$ and $36 \pm 4 \mathrm{~mL} / \mathrm{kg} / \mathrm{h}$ for HCO CVVHD and HFM CVVHDF respectively. IC, instantaneous clearance; CVVHD, continuous veno-ve- nous hemodialysis; CVVHDF, continuous veno-venous hemodiafiltration; HCO, high cut-off; HFM, high-flux membrane; $\mathrm{Cl}$., clearance; Ur., urea; Cr., creatinine; $\beta_{2} \mathrm{M}, \beta_{2}$-microglobulin. ${ }^{*} p<$ $0.05 \mathrm{HCO}$ vs. HFM.

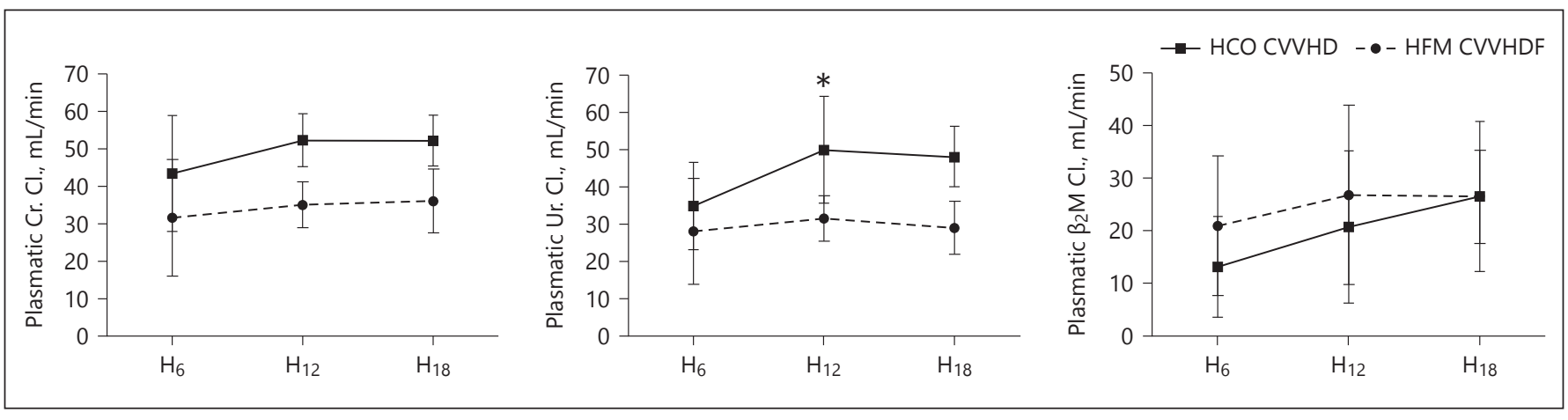

Fig. 3. PCs of creatinine, urea and $\beta_{2} \mathrm{M}$ at $\mathrm{H}_{6}, \mathrm{H}_{12}, \mathrm{H}_{18}$ of $\mathrm{HCO}$ CVVHD and of HFM CVVHDF. Dialysis dose was at $21 \pm 6$ and $36 \pm 4 \mathrm{~mL} / \mathrm{kg} / \mathrm{h}$ for HCO CVVHD and HFM CVVHDF respectively. PC, plasmatic clearance; CVVHD, continuous veno-venous

Cytokines plasmatic measurements showed a significant heterogeneity between individuals before initiation of RRT, but their variations after HCO CVVHD and HFM CVVHDF sessions remained totally similar. Thus, mean levels of pro- (TNF- $\alpha$, IL-1 $\alpha$, IL-1 $\beta$, IL-2, IL-6, IL-8) and anti- (IL-4, IL-10) inflammatory cytokines were not significantly different before and after RRT sessions (Table 2 and Fig. 5). Analysis of plasmatic concentrations of EGF, VEGF, and MCP-1, before and after HCOHD and HFMHDF sessions showed no significant differences (Table 2 and Fig. 6).

\section{Discussion}

In this study, we investigated the efficiency of $\mathrm{HCO}$ membrane dialyzer CVVHD compared to an HFM filter CVVHDF. Equal blood and dialysate flows were set in hemodialysis; CVVHDF, continuous veno-venous hemodiafiltration; HCO, high cut-off, HFM, high-flux membrane; Cl., clearance; Ur., urea; Cr., creatinine; $\beta_{2} \mathrm{M}, \beta_{2}$-microglobulin. ${ }^{*} p<0.05$ $\mathrm{HCO}$ vs. HFM. both modalities, but an infusate flow of $2,000 \mathrm{~mL} / \mathrm{h}$ was added in CVVHDF. Our data show that HCO CVVHD achieved an adequate dialysis dose with a fair hemodynamic tolerance compared to HFM HDF. Despite the use of a lower flow (dialysate: 2 vs. $4 \mathrm{~L} / \mathrm{h}$ ), the same level of $\beta_{2} \mathrm{M}$ clearance, a surrogate of middle-size molecule depuration, was reached without significant albumin losses with HCO CVVHD as compared to HFM HDF. HCO CVVHD did not induce an overproduction of both oxidative stress and pro- or anti-inflammatory cytokines.

HCO membrane may be defined as a membrane with a pore size around $0.008-0.01 \mu \mathrm{m}, 2-3$ times that of HFM $(0.003-0.006 \mu \mathrm{m})$. This increase in pore size enhances the molecular weight cut-off of the membranes to $100 \mathrm{kDa}$ in vitro and to approximately $50-60 \mathrm{kDa}$ in blood [29]. However, current dialysis membranes do not have pores of a uniform size that can translate with $\mathrm{HCO}$ membranes 


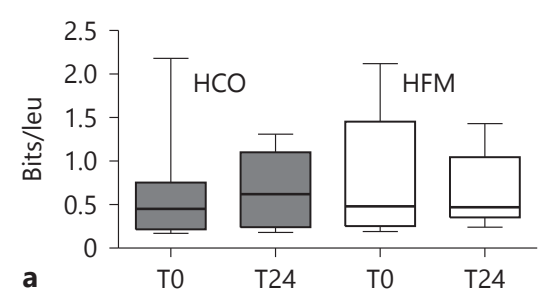

Fig. 4. Basal (a) and after PMA stimulation (b) anion superoxide production before and after HCO CVVHD and of HFM CVVHDF sessions. Values are shown as mean and SD. CVVHD, continuous

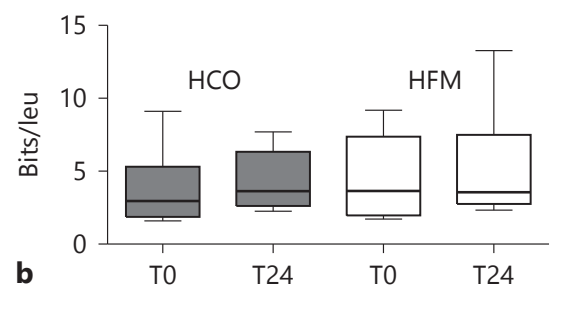

veno-venous hemodialysis; CVVHDF, continuous veno-venous hemodiafiltration; HCO, high cut-off; HFM, high-flux membrane; PMA, Phorbol 12-Myristate 13-Acetate.

Table 2. Plasma concentrations of pro and anti-inflammatory cytokines and growth factors

\begin{tabular}{|c|c|c|c|c|c|c|}
\hline pg/mL, median (IQR) & \multicolumn{3}{|l|}{ HCO CVVHD } & \multicolumn{3}{|c|}{ HFM CVVHDF } \\
\hline IL-6 & $68.8(94.6)$ & $65.9(108.1)$ & 0.7 & $63.2(60.5)$ & $77.4(34.5)$ & 0.9 \\
\hline IL-1a & $0.3(0.6)$ & $0.3(0.4)$ & 0.1 & $0.3(0.5)$ & $0.2(0.5)$ & 0.7 \\
\hline IL- $1 \beta$ & $1.6(2.5)$ & $1.2(2.1)$ & 0.6 & $1.8(2.4)$ & $1.4(2.2)$ & 0.8 \\
\hline IL-8 & $114.6(181.2)$ & $62.5(119.3)$ & 0.09 & $54.2(56.9)$ & $57.4(60.8)$ & 0.1 \\
\hline IL-10 & $3.0(7.7)$ & $2.5(9.9)$ & 0.7 & $2.4(10.3)$ & $2.4(7.5)$ & 0.9 \\
\hline VEGF & $281.6(482.1)$ & $157.0(205.0)$ & 0.6 & $165.7(167.3)$ & $247.4(157.7)$ & 0.5 \\
\hline MCP-1 & $424.7(241.0)$ & $276.3(399.9)$ & 0.2 & $354.8(354.4)$ & $322.0(709.1)$ & 0.3 \\
\hline EGF & $40.0(44.0)$ & $12.4(20.7)$ & 0.09 & $13.4(74.7)$ & $12.7(21.7)$ & 0.3 \\
\hline
\end{tabular}

$p$ value: T0 vs. T24 h.

CVVHD, continuous veno-venous hemodialysis; CVVHDF, continuous veno-venous hemodiafiltration; HCO, high cut-off, HFM, high-flux membrane; TNF- $\alpha$, tumor necrosis factor; INF G, interferon gamma; EGF, endothelial growth factor; VEGF, vascular endothelial growth factor; MCP-1, macrophage chemoattractive protein 1; IL, interleukins.

to the loss of essential proteins such as albumin. We sought therefore to evaluate in this study CVVHD with HCO membrane in ICU AKI patients regarding its efficiency, clearance of $\beta_{2} \mathrm{M}$, biocompatibility, and removal of mediators of inflammation as compared to HFM CVVHDF. Knowing that only convective therapy lead to removal of medium-sized molecules, we do compare in purpose HCO CVVHD to CVVHDF.

During HCO CVVHD, we observed less hypotensive episodes than during HDF sessions and no pyrogenic reactions. In addition, HCO CVVHD, although performed with lower flows and dialysis dose, permitted a satisfactory removal of small molecules (urea and creatinine) compared to HFM HDF. Plasmatic and ICs of urea and creatinine were above $30 \mathrm{~mL} / \mathrm{min}$ and remained stable along 24-h treatment. Schmidt et al. [30] compared HCO and HFM membrane by using equal level of flows and did not observe a difference in the clearance of small molecules. By contrast, HCO membrane induced a greater, though not significant, elimination of $\beta_{2} \mathrm{M}$ (a middle size molecule: 500-20,000 Da) in comparison to HFM. Schmidt et al. [30] demonstrated a significant higher amount of eliminated middle-molecules in HCO-treated patients as compared to those treated with HFM. In settings of chronic hemodialyzed patients, similar results were reported [31,32]. Our data may suggest that HCO HD would permit the removal of molecules with medium molecular weight including myoglobin, free light chains, and other uremic toxins. This effect would be in great concern in the critically ill with severe rhabdomyolysis and with AKI with cast nephropathy. Indeed, it was shown in a case series of 11 
Fig. 5. Mean plasmatic concentrations of pro- (TNF- $\alpha$ and IL-6) and anti-inflammatory cytokines (IL-4, IL-10) before and after HCO CVVHD and of HFM CVVHDF sessions. Values are shown as mean and SD. CVVHD, continuous veno-venous hemodialysis; CVVHDF, continuous venovenous hemodiafiltration; $\mathrm{HCO}$, high cutoff; HFM, high-flux membrane; TNF- $a$, tumor necrosis factor alpha; IL, interleukins.
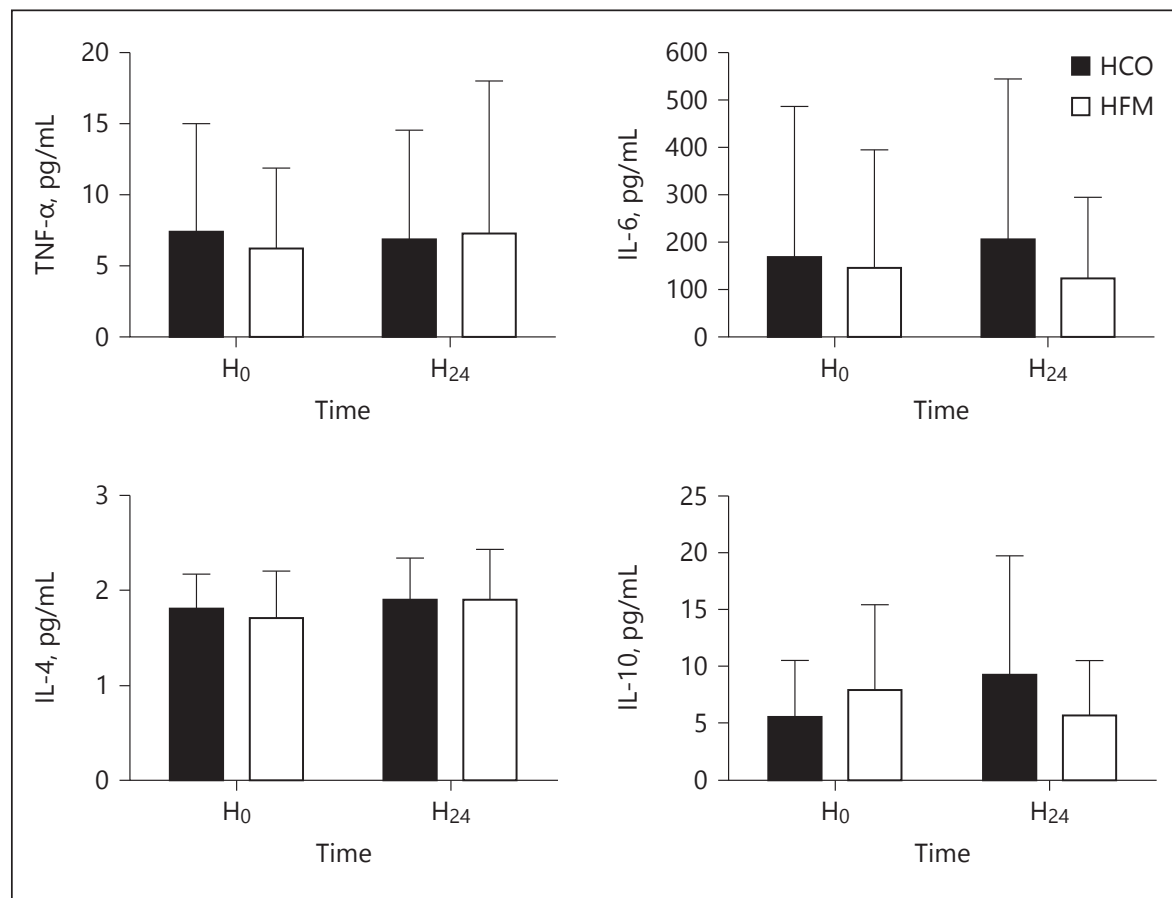


Fig. 6. Mean plasmatic concentrations of EGF, VEGF, MCP-1 before and after HCO CVVHD and of HFM CVVHDF sessions. Values are shown as mean and SSD. EGF, endothelial growth factor; VEGF, vascular endothelial growth factor; MCP-1, macrophage

chemoattractive protein-1; CVVHD, continuous veno-venous hemodialysis; CVVHDF, continuous veno-venous hemodiafiltration; HCO, high cut-off; HFM, high-flux membrane.

patients with severe rhabdomyolysis and dialysis-dependent AKI that HCOHD allowed for rapid and effective removal of myoglobin (molecular weight: $17.8 \mathrm{kDa}$ ) from the circulation [33]. Encouraging results have also been obtained in AKI with cast nephropathy with effectiveness of light chain extraction by HCO dialyzers HD $[34,35]$. This effect may be related to the increase in pore size typically 2 to 3 times that of HFMs that enhances the molecular weight cut-off of the membranes to $100 \mathrm{kDa}$ in vitro, and to approximately $50-60 \mathrm{kDa}$ in blood.

One potential drawback of large pore membranes can be the loss of albumin, despite its rather high molecular weight of $65 \mathrm{kDa}$. Previous studies reported a difference in albumin elimination between HCO and HFM but without statistical significance [30-32]. In the study by Schmidt et al. [30], albumin elimination was about 1.0$1.7 \mathrm{~g} / 10 \mathrm{~h}$ of HCO HD. We found a decrease of albuminemia after $24 \mathrm{~h}-\mathrm{HCO}$ treatment comparable to that of HFM HDF. In fact, total extracted protein was below $4 \mathrm{~g} / 24 \mathrm{~h}$, was, in accepted ranges, below $4 \mathrm{~g} / 24 \mathrm{~h}$ [36] and albumin was undetectable in the effluent. 
The use of large pore membranes could also activate the inflammatory system through a reverse diffusion of the dialysate fluid in the patient's blood stream. Basal and after PMA stimulation production rate of superoxide anion by leukocytes at the beginning and at the end of each session was not significantly different with the 2 modalities. Cytokine induction has also been considered the trigger of the inflammatory response and a critical parameter of dialysis biocompatibility during RRT [37] and high levels of pro-inflammatory cytokines have been associated with increased mortality in AKI $[38,39]$. We found that both pro- and anti-inflammatory cytokines plasma levels did not increase after HCO HD, suggesting that it might not alter the balance of cytokines production. Other studies reported, like our study, the lack of cytokines reduction by HCO membrane [40]. Enhanced production of growth factors after endothelial activation has been reported in sepsis-related AKI leading to increased capillary permeability, systemic vasodilatation, and multiorgan failure $[41,42]$. Both HDF and HD sessions were not associated with an increased production of VGEF, EGF, and MCP-1 in our patients. Chancharoenthana et al. [43] reported, however, that HDF provided a significant removal of VEGF and was associated with better renal outcome as compared to HFM HD.

We must acknowledge some limitations to the study. First, our work shares the limitations of single-center studies. Our unit is indeed familiar with both hemodialysis and hemofiltration therapies that are not the general rule in ICU settings. Second, the number of patients included may be considered small, but using a randomized crossover designed study allowed intraindividual comparison of dialyzers. Third, we estimated cytokines re- moval by plasma measurements before and after the session. It would be better to measure cytokines concentrations in both arterial and venous lines to best evaluate their potential removal through the filters. However, our concern was to demonstrate any decrease of cytokines in systemic circulation that was not observed in our study. Fourth, discussion related to the clinical relevance of our findings, especially that related to the removal of middle molecules, remains controversial. Though the utility of an HFM has been demonstrated in terms of treatment efficiency and patient's survival in chronic hemodialysis patients [17, 18, 44, 45], such has never been demonstrated in the field of AKI. However, a recent study showed that HCO CVVHD was associated with a significant reduction in SOFA score in a cohort of patients with septic shock and AKI [46].

\section{Conclusion}

In patients with ICU AKI, HCO membranes CVVHD appear to be well tolerated and are effective in the clearance of small solutes and removal of $\beta_{2} \mathrm{M}$ compared with HFM used in conventional CVVH/DF. It induces neither a significant protein loss nor an overproduction of superoxide anion. The clinical relevance of such a performance, however, remains to be proven.

\section{Disclosure Statement}

The authors declare that they have no competing interests to disclose.

\section{References}

1 Metnitz PG, Krenn CG, Steltzer H, Lang T, Ploder J, Lenz K, et al: Effect of acute renal failure requiring renal replacement therapy on outcome in critically ill patients. Crit Care Med 2002;30:2051-2058.

2 Hoste EAJ, Lameire NH, Vanholder RC, Benoit DD, Decruyenaere JM, Colardyn FA: Acute renal failure in patients with sepsis in a surgical ICU: predictive factors, incidence, comorbidity, and outcome. J Am Soc Nephrol 2003;14:1022-1030.

3 Uchino S, Kellum JA, Bellomo R, Doig GS, Morimatsu H, Morgera S, et al: Acute renal failure in critically ill patients: a multinational, multicenter study. JAMA 2005;294:813-818.

4 Lameire N, Van Biesen W, Vanholder R: Acute renal failure. Lancet 2005;365:417-430.
5 Cruz DN, Bolgan I, Perazella MA, Bonello M, de Cal M, Corradi V, et al: North East Italian prospective hospital renal outcome survey on acute kidney injury (NEiPHROSAKI): targeting the problem with the RIFLE Criteria. Clin J Am Soc Nephrol 2007;2:418425.

6 Vinsonneau C, Camus C, Combes A, Costa de Beauregard MA, Klouche K, Boulain T, et al: Continuous venovenous haemodiafiltration versus intermittent haemodialysis for acute renal failure in patients with multiple-organ dysfunction syndrome: a multicentre randomised trial. Lancet 2006;368: 379-385.

7 Mehta RL, McDonald B, Gabbai FB, Pahl M, Pascual MT, Farkas A, et al: A randomized clinical trial of continuous versus intermittent dialysis for acute renal failure. Kidney Int 2001;60:1154-1163.

8 Guerin C, Girard R, Selli JM, Ayzac L: Intermittent versus continuous renal replacement therapy for acute renal failure in intensive care units: results from a multicenter prospective epidemiological survey. Intensive Care Med 2002;28:14111418.

9 Waldrop J, Ciraulo DL, Milner TP, Gregori D, Kendrick AS, Richart CM, et al: A comparison of continuous renal replacement therapy to intermittent dialysis in the management of renal insufficiency in the acutely III surgical patient. Am Surg 2005;71:3639. 
10 Rouby JJ, Rottembourg J, Durande JP, Basset JY, Degoulet P, Glaser P, et al: Hemodynamic changes induced by regular hemodialysis and sequential ultrafiltration hemodialysis: a comparative study. Kidney Int 1980;17:801810.

11 Vinsonneau C, Benyamina M: Quelles techniques pour le traitement de la défaillance rénale aigue en reanimation? Réanimation 2009; 18:397-406

12 Schortgen F, Soubrier N, Delclaux C, Thuong M, Girou E, Brun-Buisson C, et al: Hemodynamic tolerance of intermittent hemodialysis in critically ill patients: usefulness of practice guidelines. Am J Respir Crit Care Med 2000; 162:197-202.

13 Pereira BJ: Cytokine production in patients on dialysis. Blood Purif 1995;13:135-146.

14 Locatelli F, Di Filippo S, Manzoni C: Removal of small and middle molecules by convective techniques. Nephrol Dial Transplant 2000;15(suppl 2):37-44.

15 Joannes-Boyau O, Honore PM, Boer W: Hemofiltration: the case for removal of sepsis mediators from where they do harm. Crit Care Med 2006;34:2244-2246.

16 Vanholder R, Baurmeister U, Brunet P, Cohen G, Glorieux G, Jankowski J, et al: A bench to bedside view of uremic toxins. J Am Soc Nephrol 2008;19:863-870.

17 Locatelli F, Martin-Malo A, Hannedouche T, Loureiro A, Papadimitriou M, Wizemann V, et al: Effect of membrane permeability on survival of hemodialysis patients. J Am Soc Nephrol 2009;20:645-654.

18 Chauveau P, Nguyen H, Combe C, Chêne G, Azar R, Cano N, et al: Dialyzer membrane permeability and survival in hemodialysis patients. Am J Kidney Dis 2005;45:565-571.

19 Davenport A: Anticoagulation for continuous renal replacement therapy. Contrib Nephrol 2004;144:228-238.

20 Monchi M, Berghmans D, Ledoux D, Canivet JL, Dubois B, Damas P: Citrate vs. heparin for anticoagulation in continuous venovenous hemofiltration: a prospective randomized study. Intensive Care Med 2004;30:260265.

21 Canaud B, Morena M, Cristol JP, Krieter D: Beta2-microglobulin, a uremic toxin with a double meaning. Kidney Int 2006;69:12971299.

22 De Vriese AS, Colardyn FA, Philippé JJ, Vanholder RC, De Sutter JH, Lameire NH: Cytokine removal during continuous hemofiltration in septic patients. J Am Soc Nephrol 1999; 10:846-853.

23 Kanagasundaram NS, Larive AB, Paganini EP: A preliminary survey of bacterial contamination of the dialysate circuit in continuous veno-venous hemodialysis. Clin Nephrol 2003;59:47-55.
24 Moore I, Bhat R, Hoenich NA, Kilner AJ, Prabhu M, Orr KE, Kanagasundaram NS: A microbiological survey of bicarbonate-based replacement circuits in continuous veno-venous hemofiltration. Crit Care Med 2009;37: 496-500.

25 Kellum JA, Lameire N; KDIGO AKI Guideline Work Group: Diagnosis, evaluation, and management of acute kidney injury: a KDIGO summary (part 1). Crit Care 2013;17:204.

26 NKF-DOQI clinical practice guidelines for hemodialysis adequacy. Am J Kidney Dis 1997;30(suppl 2):S38-S42.

27 Ventura E, Durant R, Jaussent A, Picot MC Morena M, Badiou S, et al: Homocysteine and inflammation as main determinants of oxidative stress in the elderly. Free Radic Biol Med 2009;46:737-744.

28 Dupuy AM, Lehmann S, Cristol JP: Protein biochip systems for the clinical laboratory. Clin Chem Lab Med 2005;43:1291-1302.

29 Calaf R, Cerini C, Génovésio C, Verhaeghe P, Jourde-Chiche N, Bergé-Lefranc D, et al: Determination of uremic solutes in biological fluids of chronic kidney disease patients by HPLC assay. J Chromatogr B Analyt Technol Biomed Life Sci 2011;879:2281-2286.

30 Schmidt JJ, Hafer C, Clajus C, Hadem J, Beutel G, Schmidt BM, et al: New high-cutoff dialyzer allows improved middle molecule clearance without an increase in albumin loss: a clinical crossover comparison in extended dialysis. Blood Purif 2012;34:246-252.

31 Lee D, Haase M, Haase-Fielitz A, Paizis K, Goehl H, Bellomo R: A pilot, randomized, double-blind, cross-over study of high cut-off versus high-flux dialysis membranes. Blood Purif 2009;28:365-372.

32 Pellicano R, Polkinghorne KR, Kerr PG: Reduction in beta2-microglobulin with superflux versus high-flux dialysis membranes: results of a 6-week, randomized, double-blind, crossover trial. Am J Kidney Dis 2008;52:93101.

33 Heyne N, Guthoff M, Krieger J, Haap M, Häring HU: High cut-off renal replacement therapy for removal of myoglobin in severe rhabdomyolysis and acute kidney injury: a case series. Nephron Clin Pract 2012; 121:c159-c164

34 Martín-Reyes G, Toledo-Rojas R, Torres-de Rueda Á, Sola-Moyano E, Blanca-Martos L, Fuentes-Sánchez L, et al: Haemodialysis using high cut-off dialysers for treating acute renal failure in multiple myeloma. Nefrol Publicacion 2012;32:35-43.

35 Walther C, Podoll AS, Finkel KW: Treatment of acute kidney injury with cast nephropathy. Clin Nephrol 2014;82:1-6.
36 Krieter DH, Hackl A, Rodriguez A, Chenine L, Moragues HL, Lemke HD, et al.: Proteinbound uraemic toxin removal in haemodialysis and post-dilution haemodiafiltration. Nephrol Dial Transplant 2010;25:212218

37 Vaslaki L, Weber C, Mitteregger R, Falkenhagen $\mathrm{D}$ : Cytokine induction in patients undergoing regular online hemodiafiltration treatment. Artif Organs 2000;24:514-518.

38 Simmons EM, Himmelfarb J, Sezer MT, Chertow GM, Mehta RL, Paganini EP, et al: Plasma cytokine levels predict mortality in patients with acute renal failure. Kidney Int 2004;65:1357-1365.

39 Kadiroglu AK, Sit D, Atay AE, Kayabasi $\mathrm{H}$ Altintas A, Yilmaz ME: The evaluation of effects of demographic features, biochemical parameters, and cytokines on clinical outcomes in patients with acute renal failure. Ren Fail 2007;29:503-508.

40 Morgera S, Slowinski T, Melzer C, Sobottke V, Vargas-Hein O, Volk T, et al: Renal replacement therapy with high-cutoff hemofilters: impact of convection and diffusion on cytokine clearances and protein status. Am J Kidney Dis 2004;43:444453

41 van der Flier M, van Leeuwen HJ, van Kessel KP, Kimpen JL, Hoepelman AI, Geelen SP: Plasma vascular endothelial growth factor in severe sepsis. Shock 2005;23:35-38.

42 Pickkers P, Sprong T, Eijk Lv, Hoeven Hv, Smits P, Deuren Mv: Vascular endothelial growth factor is increased during the first 48 hours of human septic shock and correlates with vascular permeability. Shock $2005 ; 24$ : 508-512.

43 Chancharoenthana W, Tiranathanagul K, Srisawat N, Susantitaphong P, Leelahavanichkul A, Praditpornsilpa K, et al: Enhanced vascular endothelial growth factor and inflammatory cytokine removal with online hemodiafiltration over high-flux hemodialysis in sepsis-related acute kidney injury patients. Ther Apher Dial 2013;17:557-563.

44 Eknoyan G, Beck GJ, Cheung AK, Daugirdas JT, Greene T, Kusek JW, et al: Effect of dialysis dose and membrane flux in maintenance hemodialysis. N Engl J Med 2002;347:20102019.

45 Cheung AK, Rocco MV, Yan G, Leypoldt JK, Levin NW, Greene T, et al: Serum beta- 2 microglobulin levels predict mortality in dialysis patients: results of the HEMO study. J Am Soc Nephrol 2006; 17:546-555.

46 Villa G, Chelazzi C, Morettini E, Zamidei L, Valente S, Caldini AL, et al: Organ dysfunction during continuous veno-venous high cut-off hemodialysis in patients with septic acute kidney injury: a prospective observational study. PLoS One 2017;12:e0172039. 